\title{
Primary care physicians and infectious diseases' notification
}

Authors

Predrag Duric ${ }^{1}$

Svetlana Ilić

${ }^{1}$ Assistant Professor, MD, $\mathrm{MSc}, \mathrm{PhD}$, - Chief of HIV, hepatitis, SPI and TB Unit ${ }^{2} \mathrm{MD}$, Chief of Unit for Infectious disease surveillance, intestinal, vector borne diseases and zoonosis
Submitted on: 12/16/2010 Approved on: 12/16/2010

Correspondence to:

Predrag Duric

Futoska 121

21000 Novi Sad

AP Vojvodina

Serbia

duricp@gmail.com

We declare no conflict of interest.
Systematic reporting of infectious diseases by health workers and laboratories provides basic data needed for evaluating public health conditions. ${ }^{1}$ Primary care physicians $(n=277)$ involved in routine infectious disease reporting were involved in this study aiming to determine their attitudes towards infectious disease reporting and to measure their medical knowledge, which is important for infectious disease notification. Most of the incorrect answers towards knowledge on diagnoses registered in Autonomous Province of Vojvodina in the previous year were related to tetanus $(61.0 \%$ incorrect answers - examinees thought the disease was not notified in the previous year at all); psittacosis (59.2\%); Q fever (56.1\%); hemorrhagic fever with renal syndrome (54.1\%); brucellosis (44.0\%); and leptospirosis (38.4\%). All of these diseases are zoonosis and all of them require hospitalization and can be fatal. Lyme's disease is widespread in AP Vojvodina. Yet, $14.4 \%$ of physicians were not aware of the prevalence of Lyme's disease. With regards to unregistered infectious diseases in the AP Vojvodina in the previous year (and in many cases, even decades back), the most incorrect answers were related to measles (41.5\%) and pertussis (19.1\%). There was a single case of measles reported in the AP Vojvodina since 2000 with the exception of the measles outbreak in 2007 (22 cases). Cases of pertussis are diagnosed very rarely and not every year. On the other hand, it must be mentioned that more than $8 \%$ of physicians thought that diphtheria was still present in Vojvodina (it was eliminated in 1976), and about $5 \%$ of physicians thought human rabies was still present in Vojvodina (was eliminated in 1964). The worst results for familiarity with diseases that require mandatory reporting were obtained for congenital rubella syndrome (40.1\% of incorrect answers), followed by streptococcal pneumonia, diseases caused by $H$. influenzae, lambliasis, and abdominal typhus. Closer collaboration and improved communication between public health officials and primary health physicians, and the appointment of personnel dedicated to the notification and reporting of infectious diseases in addition to improved training of primary care physicians could advance infectious disease reporting and thus increase infectious disease surveillance. ${ }^{2,3,4}$

[Braz J Infect Dis 2011;15(2):188]@Elsevier Editora Ltda.

\section{REFERENCES}

1. World Health Organization Regional Office for Europe. Technical cooperation. 2003 [cited 2003 Dec 30]. Available at: http://www.who.dk/ surveillance/cooperation/20040528_1.

2. Keller M, Biench M, Tolentino $\mathrm{H}$ et al. Use of unstructured event-based reports for global infections disease surveillance. Emerg Infect Dis. 2009; 15(5):689-95.

3. Prato B, Napoli C, Barbuti G, Germinario C, Lopalco PL. General practitioners and mandatory surveillance of communicable diseases: a descriptive study in Puglia (South Italy) [in Italian]. Ann Ig. 2004; 16(3):449-55.

4. Seneviratne SL, Gunatilake SB, de Silva HJ. Reporting notifiable diseases: methods for improvement, attitudes and community outcome. Trans R Soc Trop Med Hyg. 1997r; 91(2):135-7 